\title{
Impact of Management Technique on Self-Care of Chemotherapy Side- effects Among Leukemic Children
}

\author{
Eman Abd Elsamea Elguoshy, Assistant Lecturer \\ Pediatric Nursing, Faculty of Nursing, Mansoura University \\ Heba Ezzat Kamhawy, Lecturer \\ Pediatric Nursing, Faculty of Nursing, Mansoura University \\ Wafaa Mahmoud AbdEl-Kader, Assistant professor \\ Pediatric Nursing, Faculty of Nursing, Alexandria University \\ Shadia Mostafaa El-Sallab, Professor \\ Pediatrics, Faculty of Medicine, Mansoura University
}

\begin{abstract}
Background: Leukemia is the most common form of childhood cancer and is an abnormal unrestricted proliferation of immature white blood cells in the bone marrow and certain blood forming tissues. Chemotherapy is the treatment of choice and is accompanied by several side-effects. Objective: To identify impact of management on self-care of chemotherapy side-effects among leukemic children, to find out patients self-care deficit and to evaluate the effectiveness of teaching side-effect management technique (SEMT). Setting: The study was conducted at In-patient and Out-patient pediatric units at El-Mansoura University Oncology Center. Subjects: 110 children with leukemia. Tools: Two tools were used to elicit the necessary data; the leukemic children's structured interview schedule, and the Karnovski Scale used to assess the performance status of the patients and the Side-Effect Management Technique. Results: more than two-thirds of the studied children were males $(67.3 \%)$ compared to $(32.7 \%)$ who females. Most common side-effects of chemotherapy were anorexia (84.5\%), nausea and vomiting (80.9\%), alopecia (72.7\%), fatigue (64.5\%) and stomatitis (55\%). There was statistically significant difference between measures which were used before and after SEMT to most of side-effects experienced by patients who received chemotherapy. Conclusion: Patients who received chemotherapy developed side-effects related to each drug. Side-effect management technique as nursing measures helped leukemic children to acquire self-care behaviors to manage raised side-effects. Recommendations:
\end{abstract} ASNJ Vol.16 No. 1, 2014 
Management of Chemotherapy Side-effects

Health teaching plan should be available to the patient and his family, and nurses should discuss with physicians different protocols of treatment to have information about different cytotoxic drugs.

Kevwords: Leukemia, Chemotherapy, Sid-effect management technique.

\section{Introduction}

Leukemia refers to cancers of the white blood cells, in which large numbers of abnormal white blood cells are produced in the bone marrow. These abnormal white cells crowd the bone marrow and flood the blood stream, but they cannot perform their proper role of protecting the body against disease because they are defective ${ }^{(1)}$. As leukemia progresses, the cancer interferes with the body production of other types of blood cells, including red blood cells and platelets. This results in anemia and bleeding problems, in addition to the increased risk of infection caused by white cell abnormalities ${ }^{(2)}$.

The most common types of leukemia are acute lymphoblastic leukemia (ALL), acute myelogenous leukemia (AML), Chronic lymphocytic leukemia (CLL), Chronic myelogenous leukemia (CML) and Hairy cell leukemia ${ }^{(3,4)}$.

The American Cancer Society in Washngton estimated that in 2009 about 44,270 new cases of leukemia would be diagnosed, and about 21,790 deaths would be attributed to the disease ${ }^{(5,6)}$. The incidence of acute leukemia in El-Mansoura University

ASNJ Vol.16 No. 1, 2014
Oncology Center in Egypt is 481 cases of children and early adolescent from 20022011years and this number increased to 541 cases during the year $2012^{(7)}$.

Treatment of ALL involves chemotherapy combined with radiotherapy and/or surgery. Chemotherapy is the most effective treatment. On the other hand, it causes several side effects which interfere with the children's quality of life. Some of these side-effects are anorexia, nausea, vomiting, dry mouth, taste and smell changes, fatigue, pallor, weight loss, infection, alopecia, bone and joint pain, fever, easy bruising, epistaxies or other hemorrhage, hepato- splenomegally and lymphadenopathy ${ }^{(8-11)}$.

The side-effect management technique (SEMT) is the self-care information presented by Dodd $(1981)^{(12)}$. For side-effect management technique to cancer patients receiving radiation therapy, in which she describes the main side-effects which are expected to be experienced by the cancer patient who is receiving radiation. It was modified to suit Egyptian children who received chemotherapy ${ }^{(13)}$. 
The nurse has a vital role in the care of the children with leukemia through providing physical and psychological interventions to minimize the complications caused by chemotherapy which can affect the children's quality of life and daily habits ${ }^{(14)}$. Orem's self-care model of nursing encourages nurses to act in a- complementary way with patients, their families and significant others in order to enable self-care to be achieved. The model might be done through identifying the individual's demands for self-care and their abilities to meet these, then determine the need for nursing intervention ${ }^{(15)}$.

Nursing intervention is necessary within Orem's framework in order to facilitate recovery from disease or injury and to help individuals cope with the effect of such threats to their self care abilities. In order to perform nurses' role, an individual requires specialized knowledge, skills and attitudes. Orem believed that nurses must be familiar with the technological and moral aspects of decisions which affect lives, health and welfare $^{(16)}$. So, the nurse plays an important role in teaching the child to carry out selfcare agency or to be a dependency care agency on his mother ${ }^{(17,18)}$.

\section{Aim of the Study}

The study aimed to:
- Identify side-effects of chemotherapy experienced by children with leukemia.

- Find out patients self-care deficits.

- Evaluate the effectiveness of teaching side-effect management technique for leukemic children on minimizing their sideeffects.

\section{Research Hypotheses:}

-Alleviate the side-effects of chemotherapy

-Improve performance of leukemic child i.e. carry out all activities of daily living.

\section{Materials and Method}

\section{Materials}

Design: It is quasi-experimental research design.

Setting: This study was conducted at Inpatient and Outpatient pediatric units at ElMansoura University Oncology Center.

Subjects: All children with leukemia, who attended the mentioned setting over a period of 6 months and fulfilled the following criteria, comprised the subjects $(n=110)$ :

- Age from 8-15years.

- Receiving second or more than second dose of chemotherapy.

Tools: Two tools were used to elicit the necessary data: 


\section{Tool I: Sociodemographic and medical} history A Structured Interview Schedule:

The leukemic children's structured interview .It was developed by the researcher to collect the following information:

A: Childrens name, age, level of education, birth order and residency.

B: Information about disease and treatment such as (diagnosis, type of leukemia, chemotherapy protocol, if the child received any medication rather than chemotherapy and other lines of treatment beside chemotherapy.

\section{Tool II:}

A- Karnovski Scale: was used to assess the performance status of the patients on six points scale.

This scale included the physical capabilities in performing activities of daily living ranging from 100-0 scale and described as:-

* 90-100 Fully active, able to carry on all daily living activities performance without restriction.

* 70-89 Restricted in physical strenuous activity but ambulatory and able to carry out work in light or secondary snature.

* 50-69 Ambulatory and capable of all selfcare but unable to carry out any activities. Up and about more than 50\% of school hours.
*30-49 Capable of only limited self-care, confined to bed or chair more than $50 \%$ of school hours.

*10-29 Completely diseased. Can't carry on self-care, totally confined to bed or chair.

* 0-9 Dead.

\section{B- Side-Effect Management technique (SEMT):}

It is the self care information presented by Dodd (1981) ${ }^{(12)}$ in her booklet side effect management technique and it is management to cancer patient who are receiving radiation therapy. This booklet was translated and validated into Arabic by Ahmed $(1984)^{(13)}$.This technique was modified to Egyptian children who are receiving chemotherapy.

It included:

A- A list of the experienced side-effects used a Likert type scale ranging from mild to severe of the side-effects.

B- Management for each side-effect and whether it minimized side-effects or not.

C- The effectiveness of each self-care behavior in alleviating each side- effect both before and after implementation of the sideeffect management technique. The effectiveness based on four points:

1-Completely alleviated

2-Minimized 
3-Still present

4-increased

\section{Method}

1. An official permission was obtained from the administrator of ElMansoura University Oncology Center to carry out the study after explaining the aim.

2. The Side-effect Management Technique (SEMT) developed by Dodd. It was modified for children receiving chemotherapy by Ahmed (1984). The Side-effect Management Technique (SEMT) was modified and subjected for each content validity by 5 expertise in pediatric nursing value of reliability equal (93\%).

3. A pilot study was conducted on eleven children to evaluate the clarity and applicability of the research tools. No modification was done.

4. Each child was interviewed individually to obtain their characteristics and their information about the disease and its management (using tool I).

5. Researcher identified side effects of chemotherapy experienced by the patient (using SEMT part A).
6. Side Effect Management Technique (SEMT) was implemented in 8 sessions. Each session lasted for half an hour. Its contents are: edema, diarrhea, anorexia, nausea, vomiting, constipation, dermatitis, rectal abscess, eye abscess, alopecia, stomatitis, abnormal gait, insomnia, fatigue, social behaviors, headache, bone pain and abdominal cramp. The information was provided and explained either individually or in groups as needed for children or dependent care agents (whenever there are similar side effects). After explaining care for the experienced side-effect, the researcher paused and asked the child and/ or dependent care agency to give in his own words and terms feedback of what has been said and any misinformation and gaps of knowledge were immediately corrected before proceeding to the next point. Encouragement was given when answers were correct in a sort of scarf and play materials.

7. At the end of the last session each child was be assessed for his capabilities using the Karnovski scale (tool II).

8. Collection of data began on November 2011 and ended on April 2012. 


\section{Ethical considerations:}

A written consent was obtained from each child and/or his caregiver for child participation in this study after explaining the purpose of the study and the confidentiality of data obtained.

\section{Statistical Analysis}

Data was analyzed using SPSS (Statistical Package for Social Sciences) version 15. Qualitative data was presented as number and percent. Wilcoxon singed ranks test was used for comparison within group. $\mathrm{P}<0.05$ was considered to be statistically significant.

\section{Results}

Table (1) shows the characteristics of the sample. The highest percentage consisted of $(42.7 \%)$ aged between 8 to less than 10 years, while the lowest percentage found among (10.9\%) aged between 14 to less than 15 years. As regards sex, the sample consisted of more than two thirds males (67.3\%), compared to one third of females $(32.7 \%)$. It is clear from the same table that the highest percentage of the studied children regarding birth order was the $1^{\text {st }}$ child (41\%), while the lowest percentage was $(7 \%)$ from $4^{\text {th }}$ child.

Table (2) represents nursing diagnoses related to side-effects of chemotherapy. This table shows health deficits according to Orem classification. Regarding functional changes, the majority of childrens' who have nutrition alteration less than body requirement as anorexia, nausea and vomiting are $84.5 \%, 80.9 \%$ respectively. Whereas the lowest percentage of the sample had diarrhea (5.5\%).

As regards structural changes disturbance in self concept as alopecia was found among $72.7 \%$ of them. Forty five point five percent of the children have alteration of mucous membrane of the mouth, but skin integrity impairment and altered protection related to abnormal gait have lowest percentages $18.2 \%, 0.9 \%$ respectively.

It is revealed from the same table that the highest percentage among children's who have behavioral changes, suffer from fatigue (64.5\%). Altered comfort related to bone pain, abdominal cramps, sleep pattern disturbance and headache were reported by $33.6 \%, 17.3 \%, 8.2 \%$ and $6.4 \%$ of children's respectively as side-effects of chemotherapy.

Effectiveness of SEMT on functional changes resulting from sideeffects of chemotherapy is presented in table (3-A). It is noticed that before teaching, measures used for children with oedema were still present for (70\%) of them and ineffective for (30\%). After SEMT, they were effective for (50\%) and decreased for (50\%). A statistically significant difference 
Management of Chemotherapy Side-effects

between the two groups was found $(\mathrm{p}=0.004)$.

As for diarrhea, measures that were used for managing it before teaching decreased in (16.7\%), still present in (66.7) and ineffective in $(16.7 \%)$. After SEMT, they were effective for $(100 \%)$. A statistically significant difference between the two groups was observed, $(\mathrm{p}=0.024)$.

Regarding anorexia, the effectiveness of measures before teaching were effective in (15.1\%), still present in (76.3\%) and ineffective in $(8.6 \%)$. After teaching, they were effective in $(74.2 \%)$ and decreased in a quarter and eight percent of children $(25.8 \%)$. There was a statistically significant difference between both groups ( $p<0.001)$.

It is revealed from the same table that, measures used for patients with nausea \& vomiting before teaching were decreased in (9\%), ineffective in (89.9\%) and effective in (1.1\%). After teaching they were effective in $(74.2 \%)$, decreased in $(25.8 \%)$. measures were effectiveness before and after teaching $(\mathrm{p}<0.001)$.

Regarding constipation, measures that were done before teaching to the children decreased in $(91.7 \%)$ and were still present in $(8.3 \%)$. After teaching measures they were effective in (75\%) and decreased in a quarter of the children (25\%). There was a significant difference between effectiveness for measures before and after teaching ( $p$ $=0.002)$.

Table (3-B) revealed the effectiveness of SEMT on structural changes resulting from side-effects of chemotherapy. Measures used to manage dermatitis before teaching decreased in $(90 \%)$, still present in $(10 \%)$. After teaching they were effective in $(85 \%)$ and decreased in (15\%). A statistically significant difference was found between the two groups $(\mathrm{p}=<0.001)$.

Effectiveness of measures that used before teaching to patients suffering from disturbance from self concept related to alopecia decreased in (11.3\%) and still present in $(87.5 \%)$. After teaching they were effective in $(58.8 \%)$ and decreased in $(41.3 \%)$. The difference was statistically significant $(\mathrm{p}=<0.001)$.

Regarding stomatitis, the effectiveness of measures used before teaching decreased in (32\%), still present in (60\%) and ineffective in $(8 \%)$. After teaching they were effective in $(72 \%)$ decreased in $(26 \%)$ and still present in $(2 \%)$. There was a statistically significant difference between both groups $(p<0.001)$. Measures taken before teaching to manage patients suffering from protection of hazards related to abnormal gait were still present in $(100 \%)$. After teaching are decreased in $(100 \%)$. 
Table (3-C) shows the effectiveness of SEMT on behavioral changes resulting from side-effects of chemotherapy. It is shown from this table that measure taken before teaching in managing patients suffering from sleep pattern disturbance decreased in (77.8\%) and were still present in $(22.2 \%)$. After teaching they were effective in $(88.9 \%)$, and decreased in $(11.1 \%)$. $\mathrm{A}$ statistically significant difference was found $(\mathrm{p}=0.004)$.

The effectiveness of measures used in managing fatigue decreased in $(2.8 \%)$, were still present in $(94.4 \%)$ and ineffective in (2.8\%). After teaching they were effective in $(74.6 \%)$, and decreased in $(25.4 \%)$. There was a statistically significant difference $(\mathrm{p}=<0.001)$.

All patients with potential alteration in social behavior, the measures before teaching were ineffective either decreased in $(10 \%)$ or still present in (90\%). After teaching it is effective in (60\%), decreased in $(40 \%)$. A statistically significant difference was found $(\mathrm{p}=<0.004)$.

Before teaching effectiveness of measures done to children's complaining from headache decreased in (42.9\%) was still present in $(57.1 \%)$. After teaching they were effective in (100\%). A statistically significant difference was found $(\mathrm{p}=<0.015)$.
It is clear from the same table that measures done to children's complaint of bone pain decreased in $(18.9 \%)$, was still present in $(81.1 \%)$. After teaching they were effective in more than- two thirds (67.6\%) and decreased in one- third of them $(32.4 \%)$. A statistically significant difference was found $(\mathrm{p}=<0.001)$.

Regarding measures done for patients complaining from abdominal cramps before teaching they decreased in (42.1\%), were still present in $(57.9 \%)$. After teaching they were effective in $(63.2 \%)$ and decreased in (31.6\%). A statistically significant difference was found $(\mathrm{p}=<0.001)$.

Table (4) shows the performance status of patients as scored before and after giving SEMT according to Karnovski scale. It is noticed that before teaching $0.9 \%$ were fully active and able to carry out all disease performance without restriction, $49.1 \%$ were restricted in physical activities but able to carry out light work. $48.2 \%$ of the sample were able to do self care and rest in bed about $50 \%$ of working hours. Only $1.8 \%$ of leukemic children are capable of only limited self-care, confined to bed or chair more than $50 \%$ of working hours. At the end of SEMT, $50 \%$ were fully active, while $48.2 \%$ of the whole samples were restricted in physical activity but able to do light work and $1.8 \%$ of children's were ambulatory and capable of all self-care but unable to carry out any work 
activities. There was a statistically significant difference between leukemic children's performance before and after SEMT $(\mathrm{p}=<0.001)$.

\section{Discussion}

Leukemia is the most common form of childhood cancer. Leukemia is an abnormal unrestricted proliferation of immature white blood cells in the bone marrow and certain blood forming tissues. These cells then infiltrate other tissues, particularly the liver, spleen, and lymph glands and replace functional cells with leukemic cells. (Hockenberry $\mathrm{MJ}$, et al. $2007)^{(21)}$.

Treatment of leukemia involves the use of chemotherapy, with or without irradiation (Ludwig WD, et al. 2003) ${ }^{(22)}$. Although chemotherapeutic drugs are being administered to palliate symptoms, prolong life and cure several types of cancers, the side-effects experienced may be frightening, painful and often embarrassing to leukemic children. (Hellenbrecht A, et al., 2009) ${ }^{(23)}$.

The nurse's role is multifaceted and involves a combination of oriented, observatory, counseling, supporting and educational skills. Her role also requires that she educates both patients and their families. This is in order to facilitate their adjustment process to the fact that the patient is now a sufferer of leukemia. The nurse is expected to help them in receiving and mastering information related to the disease process, treatment protocol, initiation to expected side-effects, interventions and home management. (Health Centers. 2012 a) ${ }^{(24)}$.

The findings of the current study revealed that more than two thirds of the studied children were males. This finding is supported by (El-Araby 2002; and Hassan 2006) who stated that the disease is more common in males than in females ${ }^{(25,26)}$. Margolin et al. (2002) mentioned that leukemia occurs more frequently in males than in females after age one year ${ }^{(27)}$. The present study showed that the highest percentages of the leukemic children were from eight to ten years of age. This finding goes in line with (Osborn et al. 2006) who mentioned that acute lymphoblastic leukemia occurs in children about eight years old ${ }^{(28)}$. But the finding of the current study contradicted with (Redaelli et al. 2013) who stated that acute lymphoblastic leukemia occurs in children less than five years old ${ }^{(29)}$. Also the present study is in contrast with (Dean Boer et al 2013) who found that the highest percentage of the leukemic children were below five years of age ${ }^{(30)}$.

Chemotherapy usually leads to many side-effects which include alopecia, nausea and vomiting, diarrhea and constipation, mouth sores and fatigue 
(Matziou et al. 2009; and Eiser (2013) $)^{(31,32)}$. Anorexia, nausea and vomiting, alopecia, stomatitis and fatigue were the most common side-effects of chemotherapy reported by most of leukemic children in the present study before starting SEMT. This may be because these side-effects are the most apparent ones.

Reinfjell et al (2008) reported that stomatitis is one of the common symptoms of leukemia and side-effects of chemotherapy (33). (Cheng, Lang, et al. 2013) cited that in their study new measure of health-related quality of life for patients with oropharangeal mucosities that, stomatitis is a relatively common distressing symptoms arising from selected treatment, for example in patients with acute leukemia, more than $75 \%$ of them receiving chemotherapy can experience stomatitis and is a highly distressing symptom since it can be extremely painful and directly influences patients' food intake and nutritional status and can therefore greatly influences treatment outcomes ${ }^{(34)}$. This fact is congruent with the results of the present study; where the majority of the studied children had stomatitis. The finding of this study might be related to effect of leukemia and chemotherapy on mucous membrane of the mucosa. Other authors as Catharina, Potting (2013) reported that in their study of oral mucositis and nurses perspective, that the rate of sever oral mucositis grade 3 or 4 exceeds ninety percent in most reports on patients who receive chemotherapy and reported most frequently oral pain, sores, tender or sensitive mouth and thick mucous among all study $\operatorname{participant}^{(35)}$.

Maternal measures used in the care of stomatitis prior to SEMT were the application of tehina and glycerin. Whereas following SEMT, oral care with sodium chloride and hydrogen peroxide were used during chemotherapy, use soft tooth brush ,rinsing mouth with warm water, administering soft, cool foods and applying lip balm to keep lips moist at all times. The effectiveness of the measures decreased stomatitis in $32 \%$ and no one removed before SEMT and it was removed in $72 \%$ after SEMT. There was a statistically significant difference in the degree of effectiveness of measures. This might be because all patients in the present study suffered from severe stomatitis and methods used before SEMT might be effective for mild and moderate but not for severe stomatitis. Measures were used to manage stomatitis after SEMT in the present study goes in line with Meeske et al. (2012) who mentioned that the use of soft diet, soft tooth brush and provide frequent mouth wash with normal saline or sodium bicarbonate are effective measures to remove stomatitis $^{(36)}$. 
Chemotherapy caused alopecia in three quarters of the studied children in the present study. This finding goes in line with Smith \& Hamline (2012) who stated that eighty percent of children receiving chemotherapy had alopecia and common among patients who receive vincristine and not common with all chemotherapeutic drugs ${ }^{(37)}$. The leukemic children have body image disturbance and have psychological implications for children with chronic illness due to effect of treatment especially alopecia that leads to feeling of low self-esteem (Bogni et al. 2013; and Rowe et al. $2013)^{(38,39)}$.

Maternal measures used in the care of alopecia were wearing their children scarf or hat before SEMT which was the main care stated in case of alopecia by mothers in the present study. This may be explained in the light of children's psychological feeling with their hair loss and they want to hide their scolded head and cover it. Whereas following SEMT, washing head with soap and water, avoiding use of hair pins or irritant shampoo, encouraging the child to cut hair before receiving chemotherapy dose because this action improving psychological status and use of ice bags on the head before exposure to chemotherapy. The effectiveness of the measures decreased alopecia in $11.3 \%$ before SEMT and it was removed in 58.8\% after SEMT. There was a statistically significant difference in the degree of effectiveness of measures. Reassurance that it was a temporary side-effect and hair is expected to grow after 3 to 6 months, but don't return to the same texture and color will reduce the distressing side-effect. Maternal measures used before SEMT and measures used by the researcher after SEMT supported by Sheng \& Eiser (2010) who cited that washing the child's head, wearing scarf or hat or wig and avoid use of hair pins are measures used for care of alopecia ${ }^{(40)}$.

The majority of children in the present study had anorexia (93), nausea and vomiting (89), due to effect of chemotherapy. These findings are supported by (Water et al. 2012; Figueroa, Jean, et al. 2013) who cited that in their study of self management of cancer treatment-related fatigue, nausea and vomiting, anorexia and oral mucositis in Chinese cancer patients that nausea and vomiting still occur in around half of the total sample consists of 277 patients treated for cancer $^{(41,42)}$. Michael, Dolgin. et al. (2013) they found in their study of anticipatory nausea and vomiting in a sample of pediatric patients with cancer who were receiving outpatient chemotherapy that forty male and female patients representing a broad range of diagnosis were interviewed with their parents concerning nausea and vomiting before and after chemotherapy. Anticipatory nausea was reported by $28.8 \%$ of the sample, 
anticipatory vomiting was present in $20 \%$ of the sample ${ }^{(43)}$. These side-effects may be occurred as a result of chemotherapy and when the food may not be appealing or when food has strong cooking smell that cause anorexia, nausea and vomiting to the children with leukemia.

Before SEMT maternal measures were either to force the child to eat or punish them and sometimes children refused food. This finding in contrast with Rizzieri et al. (2013) who stated that regarding anorexia, nausea \& vomiting parents should be relax and don't use any eating pressures and encourage their children to choose foods that are best tolerated for them ${ }^{(44)}$. Punishment of parents to their children or force them to eat this may be due to, anorexia is a major problem for parents because it is one area they feel responsible for, particularly when so many other facets of care are outside their control. So the nurse should investigate the family situation to determine if any factors e.g., conditioned aversion to food, environmental stress related to eating, controlling behavior, anger might be contributing to the problem.

After SEMT antiemetic were administered before meal. Food was served in attractive manner either cold or at room temperature. It was offered in small frequent easily digested meals. Spicy and fatty foods were avoided. It was recommended to increase fluid intake such as drinking apple juice, tea or cola and advice the child not to eat directly after receiving chemotherapy but after 2 hours. Encourage the child to eat in groups and demonstrate oral care before feeding. The child was put in comfortable position in a quite environment; there was statistical significant difference between effectiveness of measures before and after SEMT. Some authors reported anticipatory symptoms and antiemetic toxicity in pediatric oncology patients (Flushel et al. 2008) who stated that administration of initial dose of antiemetic before onset of nausea and vomiting and uncovering hospital food tray outside the child's room to reduce food odors are effective measures to alleviate nausea and vomiting. (Delamater 2011) (45,46). $^{(}$

Regarding fatigue, Hockenberry et al. (2007) stated that leukemia have the worst impact on the children's physical functioning, especially fatigue, because fatigue is considered the most common symptom during the treatment with chemotherapy ${ }^{(21)}$. More than two thirds of the studied children in the current study had fatigue. This finding agree with Yan, et al. (2013), who reported in their study of self management behaviors that fatigue is consistently reported as the most common symptom associated with cancer treatments occurring in more than three quarters of patients receiving chemotherapy ${ }^{(4)}$. This is also goes in line 
with Nail et al (2013) who stated that in their study information about chemotherapy sideeffects and the efficacy of self care activities used to deal with these side-effects for patients receiving chemotherapy. They found that the most common side-effects experienced by $81 \%$ of the subjects were fatigue $^{(48)}$.

Maternal measures used prior to SEMT regarding fatigue were to force the child to move, it decreased in $2.8 \%$. But after SEMT measures are range of motion exercise, providing rest periods between exercises, administering blood transfusion if necessary, discouraging active play and encourage food high in protein and calories are demonstrated. These measures were effective in $74.6 \%$ and decreased in $25.4 \%$. There was a statistically significant difference between effectiveness of measures before and after SEMT. Measures used after SEMT supported by Setwart et al (2010) who reported that nursing measures applied to manage fatigue are the use of quiet play, quiet exercise and good balanced diet are effective for fatigue in leukemic children undergoing chemotherapy ${ }^{(49)}$. Deficiency in children's and their mothers' knowledge regarding food high in calories and protein to provide them more energy which enable the leukemic children to maintain activities of daily living, in addition to worsening of psychological status and hopelessness of the mothers and their children are considered factors affecting presence of fatigue.

The result of Karnovski scale showed that $0.9 \%$ of the sample were fully active at the beginning of the study compared to $50 \%$ at the end. The explanation of this finding could be due to the awareness of side-effects through side-effect management technique.

Slightly less than half of the sample $49.1 \%, 42.2 \%$ respectively were semi-active at the beginning of the study compared to $(48.2 \%, 1.8 \%)$ at the end of SEMT. The results of this study may be explained in the light of the fact that children have the same side-effects and shared in their care and cooperative group therapy through SEMT and also sharing with others in play therapy, have good prognosis and medical care, and the sample of the present study started at the age of eight. This age is chosen because the child is in the phase of operational thought. In this phase he adds learned concepts to his thinking processes and has logical thought. This ability helps child to be an active learner in the present study, and they have more attention and assistance from the community.

At the end of SEMT, the patient and his family had idea about leukemia, its manifestations, different modes of treatment especially chemotherapy, its side-effect and how to manage each. The researcher thinks that this intervention helped the patient to be 
more comfortable and delayed progression of side-effects and/or complications.

The main benefit of SEMT is that the nurse, patient and mother participated actively in intervention of any arised sideeffect.

\section{Conclusion}

Based on the findings of the current study, it is concluded that patients who received chemotherapy developed sideeffects related to each drug. Side-effect management technique as nursing measures helped leukemic children to acquire self-care behaviors to manage raised side-effects. There was statistically significant difference between measures which were used before and after SEMT to most of side-effects experienced by patients who received chemotherapy.

\section{Recommendations}

The following recommendations can be made in the light of the current study results:

- Health teaching plan should be available to the patient and his family about disease, its manifestations, treatment, side-effects, preventive and curative measures before starting the chemotherapy.

- Health education can be in the form of direct patient teaching or handouts.

- Spread sheet should be established for each patient receiving chemotherapy. This sheet is considered as base line data and follow up assessment after each dose of chemotherapy.

- Nurses should have a body of knowledge about disease, its cause, side-effects of chemotherapy which should be updated through sharing in conferences, seminars.

- Nurses should discuss with physicians different protocols of treatment to have information about different cytotoxic drugs (name of medication, dose, route, possible sideeffects and the effects of medications. 
Table (1): Characteristics of the sample $(n=110)$.

\begin{tabular}{|c|c|c|}
\hline Characteristics' & $\begin{array}{c}\text { NO } \\
\mathrm{n}=\mathbf{1 1 0}\end{array}$ & $\%$ \\
\hline Age in Years & & \\
\hline 8- & 47 & 42.7 \\
\hline 10- & 20 & 18.2 \\
\hline 12- & 31 & 28.2 \\
\hline 14-15 & 12 & 10.9 \\
\hline Sex & & \\
\hline Male & 74 & 67.3 \\
\hline Female & 36 & 32.7 \\
\hline Birth Order & & \\
\hline $1^{\text {st }}$ & 45 & 41 \\
\hline $2^{\text {nd }}$ & 41 & 37 \\
\hline $3^{\text {rd }}$ & 16 & 15 \\
\hline $4^{\text {th }}$ & 8 & 7 \\
\hline Total & 110 & 100 \\
\hline
\end{tabular}


Table (2): Nursing Diagnoses Related to Side-Effects of Chemotherapy According to Orem Classification.

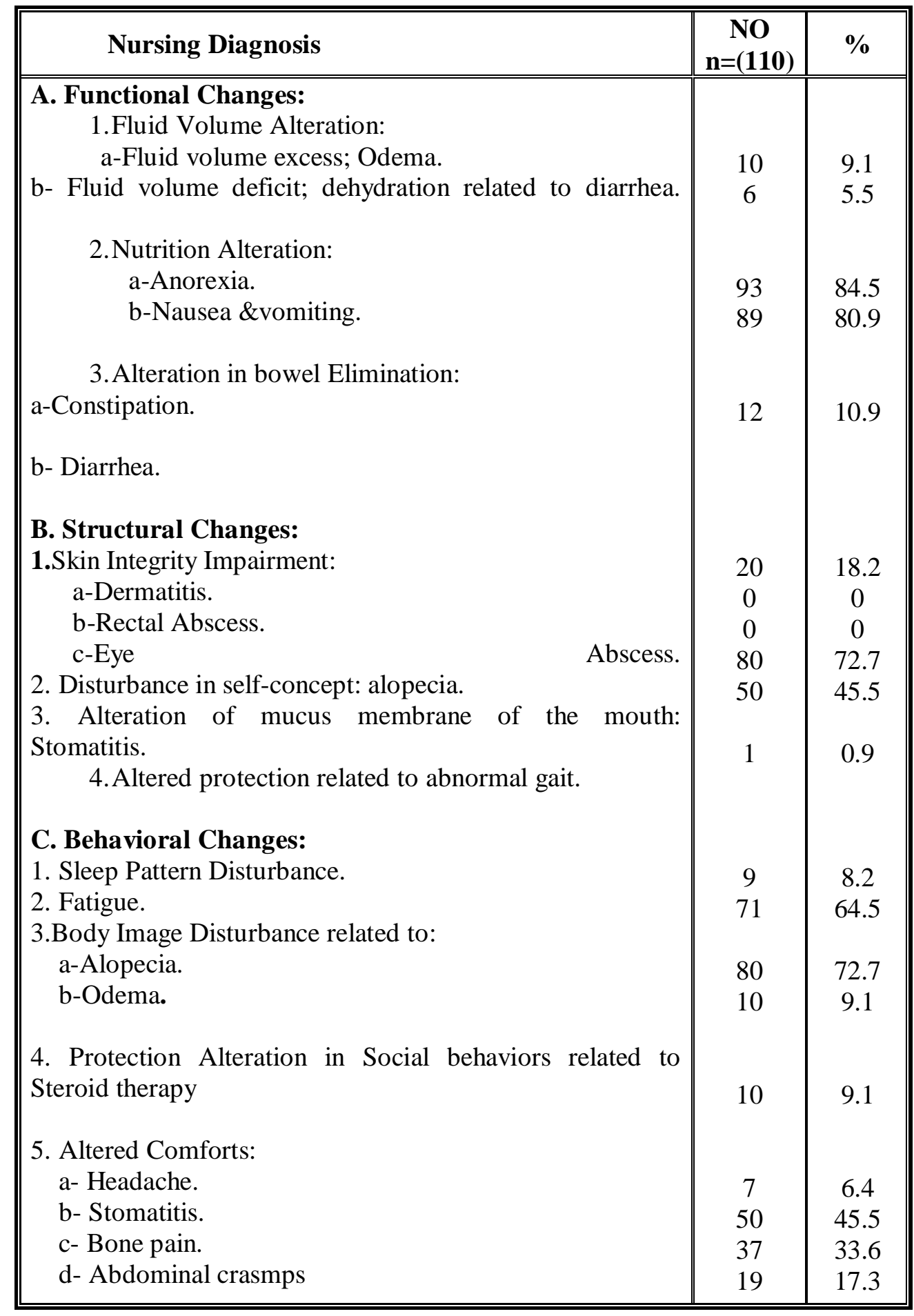


Management of Chemotherapy Side-effects

Table (3-A): Effectiveness of SEMT on Functional Changes Resulting from Side-Effects of Chemotherapy.

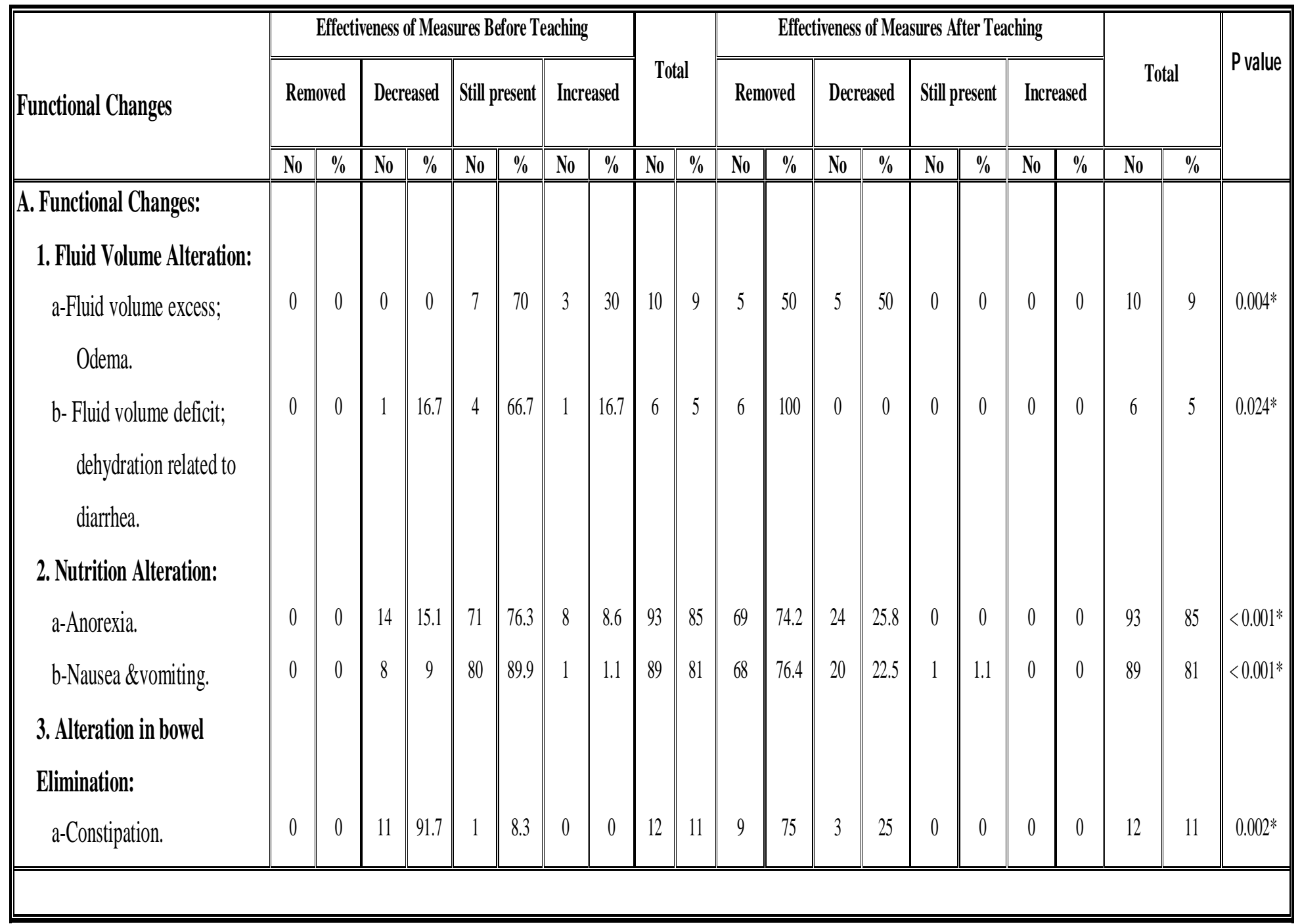

N.B: Patient might have more than one side-effect.

*Significant $P<0.05$.

ASNJ Vol.16 No. 1,2014 
Management of Chemotherapy Side-effects

Table (3-B): Effectiveness of SEMT on Structural Changes Resulting from Side-Effects of Chemotherapy.

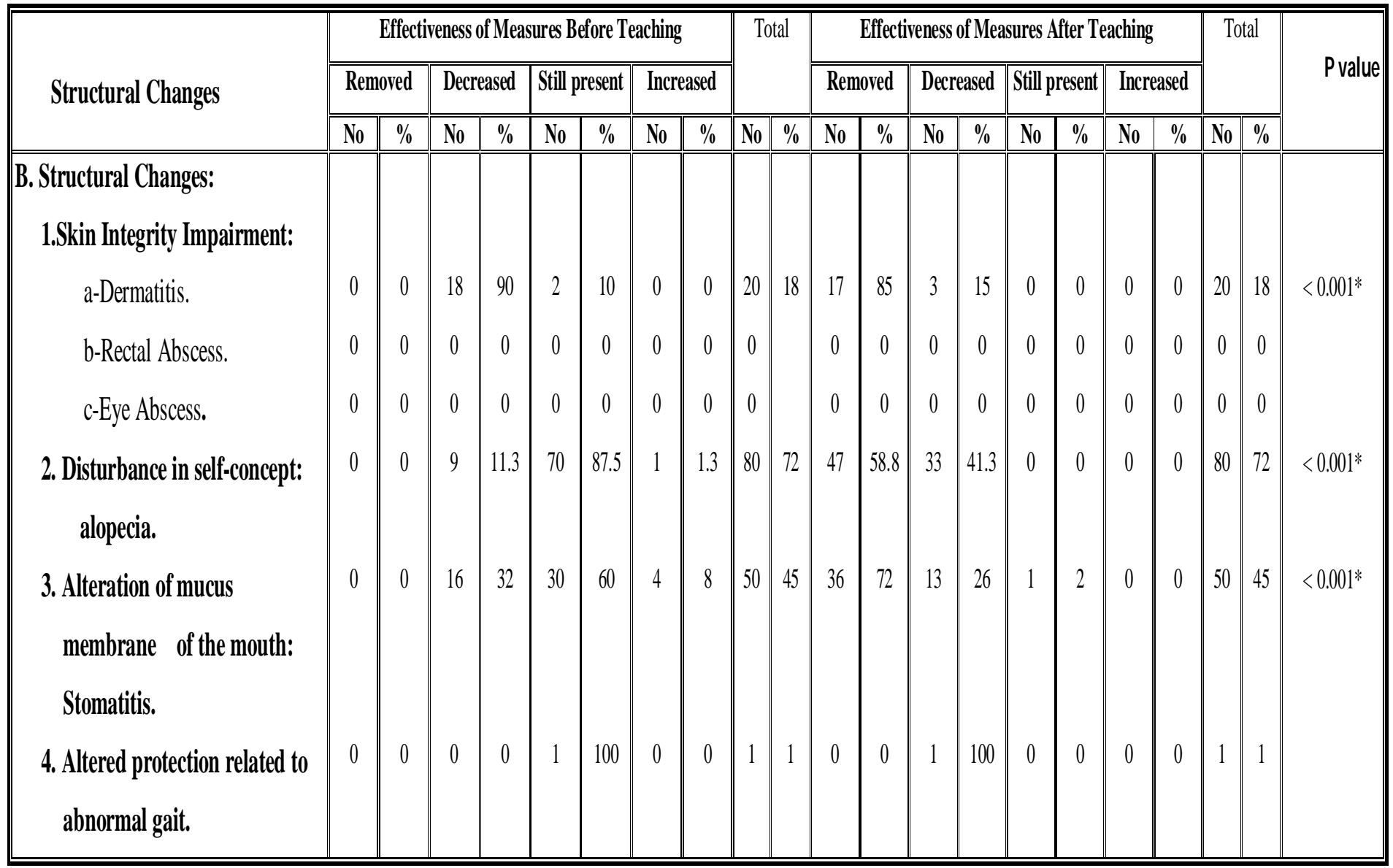

N.B: Patient might have more than one side-effect

* Significant $P<0.05$.

ASNJ Vol.16 No. 1, 2014 
Management of Chemotherapy Side-effects

Table (3-C): Effectiveness of SEMT on Behavioral Changes Resulting from Side-Effects of Chemotherapy.

\begin{tabular}{|c|c|c|c|c|c|c|c|c|c|c|c|c|c|c|c|c|c|c|c|c|c|}
\hline \multirow{3}{*}{ Behavioral Changes } & \multicolumn{8}{|c|}{ Effectiveness of Measures Before Teaching } & \multirow{2}{*}{\multicolumn{2}{|c|}{ 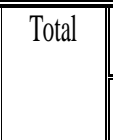 }} & \multicolumn{8}{|c|}{ Effectiveness of Measures After Teaching } & \multirow{2}{*}{\multicolumn{2}{|c|}{ Total }} & \multirow{3}{*}{ Pvalue } \\
\hline & \multicolumn{2}{|c|}{ Removed } & \multicolumn{2}{|c|}{\begin{tabular}{|l|} 
Decreased \\
\end{tabular}} & \multicolumn{2}{|c|}{\begin{tabular}{c|} 
Still present \\
\end{tabular}} & \multicolumn{2}{|c|}{$\begin{array}{l}\text { Increased } \\
\end{array}$} & & & \multicolumn{2}{|c|}{ Removed } & \multicolumn{2}{|c|}{\begin{tabular}{|l|} 
Decreased \\
\end{tabular}} & \multicolumn{2}{|c|}{ Still present } & \multicolumn{2}{|c|}{ Increased } & & & \\
\hline & $\mathrm{N}_{0}$ & $\%$ & $\mathrm{~N}_{0}$ & $\%$ & $\mathrm{~N}_{0}$ & $\%$ & No & $\%$ & \begin{tabular}{|l|lll}
$N_{0}$ \\
\end{tabular} & $\%$ & $\mathrm{~N}_{0}$ & $\%$ & $\mathrm{~N}_{0}$ & $\%$ & $\mathrm{~N}_{0}$ & $\%$ & $\mathrm{~N}_{0}$ & $\%$ & N & \% & \\
\hline \multicolumn{22}{|l|}{ C. Behavioral Changes: } \\
\hline 1. Sleep Pattern Disturbance. & 0 & 0 & 7 & 77.8 & 2 & 22.2 & 0 & 0 & 9 & 8 & 8 & 88.9 & 1 & 11.1 & 0 & 0 & 0 & 0 & 9 & 8 & 0.004 \\
\hline 2. Fatigue. & 0 & 0 & 2 & 2.8 & 67 & 94.4 & 2 & 2.8 & 71 & 65 & 53 & 74.6 & 18 & 25.4 & 0 & 0 & 0 & 0 & 71 & 65 & $<0.001^{*}$ \\
\hline 4. Protection Alteration in & 0 & 0 & 1 & 10 & 9 & 90 & 0 & 0 & 10 & 9 & 6 & 60 & 4 & 40 & 0 & 0 & 0 & 0 & 10 & 9 & $0.004 *$ \\
\hline Social behaviors related to & & & & & & & & & & & & & & & & & & & & & \\
\hline Steroid therapy. & & & & & & & & & & & & & & & & & & & & & \\
\hline 5. Altered Comforts: & & & & & & & & & & & & & & & & & & & & & \\
\hline a-Headache. & 0 & 0 & 3 & 42.9 & 4 & 57.1 & 0 & 0 & 7 & 6 & 7 & 100 & 0 & 0 & 0 & 0 & 0 & 0 & 7 & 6 & $0.015^{*}$ \\
\hline b-Bone pain. & 0 & 0 & 7 & 18.9 & 30 & 81.1 & 0 & 0 & 37 & 33 & 25 & 67.6 & 12 & 32.4 & 0 & 0 & 0 & 0 & 37 & 33 & $<0.001^{*}$ \\
\hline c- Abdominal cramps & 0 & 0 & 8 & 42.1 & 11 & 57.9 & 0 & 0 & 19 & 17 & 12 & 63.2 & 6 & 31.6 & 1 & 5.3 & 0 & 0 & 19 & 17 & $<0.001^{*}$ \\
\hline
\end{tabular}

N.B: Patient might have more than one side-effect

* Significant $P<0.05$.

ASNJ V0l.16 No. 1,2014 
Management of Chemotherapy Side-effects

Table (4): Patients KSRNOVSKI SCALE Before and After SEMT (no=110).

\begin{tabular}{|c|c|c|c|c|c|c|}
\hline \multirow[t]{2}{*}{ Grade } & \multirow[t]{2}{*}{ Scale } & \multicolumn{2}{|c|}{$\begin{array}{l}\text { Before } \\
n=(110)\end{array}$} & \multicolumn{2}{|c|}{$\begin{array}{c}\text { After } \\
n=(110)\end{array}$} & \multirow[t]{2}{*}{$P$ value } \\
\hline & & No & $\%$ & $\overline{\mathrm{No}}$ & $\%$ & \\
\hline $90-100$ & $\begin{array}{l}\text { Fully active, able to carry on all disease } \\
\text { performance Without restriction }\end{array}$ & 1 & 0.9 & 55 & 50 & \\
\hline $70-89$ & $\begin{array}{l}\text { Restricted in physical strenuous activity } \\
\text { but ambulatory and able to carry out } \\
\text { work in light or secondary nature e. g } \\
\text { light house work and office work }\end{array}$ & 54 & 49.1 & 53 & 48.2 & \\
\hline 50-69 & $\begin{array}{l}\text { Ambulatory and capable of all self-care } \\
\text { but unable to carry out any work } \\
\text { activities. Up and about more than } 50 \% \\
\text { of working hours }\end{array}$ & 53 & 48.2 & 2 & 1.8 & $<0.001 *$ \\
\hline 30-49 & $\begin{array}{l}\text { Capable of only limited self-care, } \\
\text { confined to bed or chair more than } 50 \% \\
\text { of working hours }\end{array}$ & 2 & 1.8 & 0 & 0 & \\
\hline
\end{tabular}

* Significant $\mathrm{P}<0.05$. 


\section{References}

1. Lewis SL, Sharon L, Heitkemper MM, Dirksen S, Bucher L, Obrien PG. Medical Surgical Nursing. 7th ed. Philadelphia: Mosby Company. 2007; P.717.

2. Glasper A, Richardson J. A Textbook of Children's and Young Peoples Nursing. Philadelphia: Lippincott Company. 2006; P.317.

3. Cancer Health Center. Leukemia Topic Overview. 2009. Available at: http://www.WebMD.com/community/b oards. (Retrieved on: 3/5/2011).

4. Abeloff MD, Armitage JO. Oncology. 2010. Available at: http:// www. Medicinenet.com/script/main/ art.asp?Article. (Retrieved on: 1/7/2013).

5. Black JM, Hawks JH. Medical Surgical Nursing. 8th ed. Nebraska: Saunders Elsevier Company. 2009; P.2115.

6. Stephen J, Schueler MD, John H. Leukemia Incidence. 2009. Available at: http:// www. Freemed.com/ Leukemia Incidence.htm (Retrieved on: 1/5/2013).

7. Unpublished Statistical Data from ELMansoura University Oncology Center, 2012.

8.Levin M. Leukemia Health Article. 2007. Available at: http://www.Leukemia
Information on Health Line Network.

(Retrieved on: 3/9/2013).

9.Hoffman R, Benz EJ, Shattil SS. Hematology: Basic Principles and Practice. 4thed.Washington: Churchill LivingStone. 2009; P.1124-1126. Available at: http://www.Leukemia Information On health Line.Net Works. (Retrieved on: 2013).

10. Cherath L, Kirsch B. Chronic Leukemia. 2009. Available at: http://www.answers.

com/library/oncologyencyclopedia-cid. (Retrieved on: 2/9/2013).

11. Crist WM, Pui CH, Arvin AM.((The Leukemias)). In: Nelson Textbook of Pediatrics. Behrman RE, Kliegman RM (ed.) 17th ed. Philadelphia WB: Saunders Company, 2004; PP. 470-2.

12. Dodd MG, Mocd DW .Chemotherapy: Helping patients to know the drugs they are received and their possible side-effects. Cancer Nursing; 1981; 8 (4):311-18.

13. Ahmed NT, Weheda SL .Pattern of Self-Care Behavior in Cancer Patients under Chemotherapy. The Alexandria Medical Journal. 1984; XXVI (3, 4): 185-97.

14. Burns C, Archbold P, Stewart B, Shelton K. Nursing Role in Leukemia. Wily inter science Journal. 2008; 16(3):5 Available at: http://www. 
Management of Chemotherapy Side-effects

Science Direct (Retrieved on: 4/12/2013).

15. George JB. Nursing Theories: The Base for Professional Nursing Practice. 5th ed. NewJersy: Prentice Hall., P.115.

16. Orem DE .Nursing Theories: Theory of Self Care Deficit in Nursing Practice. 2011. Available at: http://www.Current nursing.com/ Nursing theory of self care deficit theory-html. (Retrieved on: 12/2013).

17. Bowden VR, Greenberg CS .Pediatric Nursing Procedures. London: Lippincott Williams and Wilkins Company.2003; P.

18. Stanley J, Swierzewski L. Leukemia Article. 2010. Available at: http://www.Leukemia-Oncology channel.com.mht. (Retrieved on: 2/ 5/ 2013).

19. Hockenberry MJ, Wilson D, Wong D, Jackson C. Nursing Care of Infants and Children. 8th ed. St. Louis: Mosby Company, 2007; P. 1583.

20. Ludwig WD, Haferlach T, Schoch C. ((Classification of Acute Leukemias)). In: Treatment of Acute Leukemias. Pui ch (ed), 15th ed. New Jersey: Hamana Press. 2003; P.3.

21. Hellenbrecht A, Hoelzer D, Ihrig K, Messerer D, Schmenkel G, Goekbuget N .Quality of Life. Frankfurt: 2009. Available at: http://www.University
Clinic/German. (Retrieved on: January 2013).

22. Health Centers .Oncology. 2012a Available at: http://www.Medicine Net.com. (Retrieved on: 12 /2/2013).

23. El-Araby ME. Individualized Versus Group Counseling: Effect on Mothers of Leukemic Children. Unpublished Doctoral Dissertation, Faculty of Nursing, Tanta University, 2002; p.12.

24. Hassan TH. P-Glocoprotien Expression Level and its Significance in Induction of Remission in Childhood Acute Leukemia. Unpublished Master Thesis, Faculty of Medicine, Zagazig University, 2006; p.5.

25. Margolin JF, Steuber CP, Poplack DG \((Acute lymphoblastic leukemia)). In: Principles and Practice of Pediatric Oncology. Pizzo PA, Poplack DG, (eds). 4th ed. Philadelphia: Lippincott Company. 2002; PP.489-544.

26. Osborn LM, Dewitt TG, First LR, Zenel JA .Pediatrics. 15th. ed. Boston: Elsevier Mosby Company. 2006; P. 1081.

27. Redaelli A, Laskin BL, Stephens JM, Botteman MF, Pashos CL .A systemic Literature Review of the Clinical and Epidemiological burden of Acute Lymphoblastic Leukemia .European Journal Cancer Care (Engl). Mar 2013; 14(1):53-62. 
28. Den Boer ML, Van Slegtenhorst M, De Menezes RX. ((A subtype of Childhood Acute Lymphoblastic Leukemia with Poor Treatment Outcome: a genome-wide Classification Study)) Lancet oncolog.10:125. 2013. Available at: http://linkinghub.elsever.com.

(Retrieved on: 10/12/2013).

29. Matziou V, Feloni D, Mashovi M, Merkouris A. Cancer in childhood: Children's parents aspects for QOL. European Journal of Oncology Nursing, December 2009; 13(5): 409.

30. Eiser C .Children with Cancer the Quality of Life. USA: 2013. Available at: $\quad$ http://www.Informaworld. Tandf.Edu.eg. (Retrieved on: 3/ 7/2013).

31. Reinfjell T, Lofstad GE, Veenstra M, Vikan A, Diseth TH. Health-related quality of life and intellectual functioning in children with acute lymphoblastic leukemia. Acta Pediatric Journal, 2008; (96):1280-5.

32. Cheng K, Lang S, Thompson D, Tia J, Lian JR. New Measure of Health Related Quality of Life for Patients with Oropharengeal Mucositis. Cancer.2013; 109 (12): 2590-99.

33. Catharina M, Potting J. Oral Mucositis: nurses' Perspectives Thesis. Clinical Journal Oncology Nursing.2013; 9 (5): 584-92.
34. Meeske E, Bhatia S, Jenney M, Bogue MJ. Quality of life instrument: Reliability and validity. European Journal of Oncology. 2012; 145(33): 39-6.

35. Smith W, Hamlin J. Quality of life among adolescents with cancer. Journal of Pediatric Oncology Nursing. May1.2012; 112(27):133-145.

36. Bogni A, Cheng C, Liu W. Genomewide Approach to Identify Risk for Therapy-Related Myeloid Leukemia. Leukemia Journal. Feb 2013; 20 (2):239-46.

37. Rowe JM, Buck G, Burnett AK. Induction Therapy for Adults with Acute Lymphoblastic Leukemia: Results of more than 1500 Patients from the International ALL; Blood. Dec 2013; 106 (12):3760-7.

38. Sheng YU, Eiser C. Body image of Children and Adolescents with Cancer.2010. Available at: http://www.ScienceDirect. (Retrieved on: $16 / 7 / 2013)$.

39. Waters EB, Wake MA, Hesketh KD, Ashley DM. Health related quality of life of children with acute lymphocytic leukemia. International Journal of Cancer .10,2012; 103 (4): 514-8.

40. Figueroa M, Jean P, Roscoe J, Ryan J, Kohl S. Behavioral Intervention in Treating Anticipatory Nausea and 
Vomiting. Journal of Comprehensive

Cancer.2013; 5 (1): 44-50.

41. Michael J, Dolgin, Ernest R, Katz, Kathy M, Stuart E. Study of Anticipatory Nausea and Vomiting in Pediatric Cancer Patients. Pediatrics. 2013; 75 (3): 547-52.

42. Rizzieri DA, Johnson JL, Niedzwiecki D .Intensive Chemotherapy with and without Cranial Radiation for Burkitt Leukemia and Lymphoma: Final Results of Cancer and Leukemia Group B Study 9251. Cancer. Apr 2013; 100 (7):1483-48.

43. Fluchel M, Horsman JR, Furlong U, Castillo. Self and proxy reported health status \&HRQOL in survivors of childhood cancer. Pediatric Blood Cancer. 2008; 115(50):838-43.

44. Delamater MA. Quality of Life in youth with Cancer. Hematology Journal.2013; 13(1):42-54.

45. Yan Lou RN, Carthy MC. Self Management of Cancer Treatment
Related Fatigue, Nausea, Vomiting and Oral Mucositis in Chinese Cancer Pediatric Patients Thesis. Oncology Nursing Forum. 2013; 33 (4): 679-83. 46. Nail LM, Jones LS, Green D, Schipper DL, Jensen R. Information About Chemotherapy Used and Perceived Efficacy of Self Care Activities in Patients Receiving Chemotherapy Article. Oncology Nursing Forum. 2013; 18 (5):883-87.

47. Stewart AR, Bailey S. Acute Lymphoblastic Leukemia. 2010. Available at: http://www.Acute LymphoblasticLeukemia-Wikipediathe freeencyclopedia-mht.Com.

(Retrieved on: 15/3/2013). 